\title{
AUDIT COMMITTEE EFFECTIVENESS AND CONSERVATISM CONCEPT
}

\author{
DOI: 10.17261/Pressacademia.2019.1072 \\ PAP-V.9-2019(19)-p.85-89
}

\section{Gokhan Ozer ${ }^{1}$, Abdullah Kursat Merter ${ }^{2}$}

${ }^{1}$ Gebze Technical University, Department of Accounting and Finance, Gebze, Kocaeli, Turkey gokozerhan@gmail.com, ORCID: 0000-0002-3255-998X

${ }^{2}$ Gebze Technical University, Department of Accounting and Finance, Gebze, Kocaeli, Turkey akmerter@gtu.edu.tr, ORCID: 0000-0001-6874-1890

To cite this document

Ozer, G., Merter, A.K., (2019). Audit committee effectiveness and conservatism concept. PressAcademia Procedia (PAP), V.9, p.85-89

Permemant link to this document: http://doi.org/10.17261/Pressacademia.2019.1072

Copyright: Published by PressAcademia and limited licenced re-use rights only.

\begin{abstract}
Purpose- The main aim of this study is to examine the relationship between audit committee effectiveness and conservatism levels of companies identified as indicators of financial reporting quality.

Methodology- In order to achieve this aim, panel data regression analysis was performed using 1903 observations obtained from 233 nonfinancial publicly-traded company between 2008-2017.

Findings- The research findings show that the effectiveness of the audit committee is positively related to conservatism level of companies. Conclusion- As a result of the analysis, it can be said that the firms with high audit committee effectiveness will follow more conservatism accounting policies and consequently the quality of financial reporting will increase.
\end{abstract}

Keywords: Audit committee effectiveness, conservatism, basu model, panel data analysis JEL Codes: M40, M41, M42.

\section{DENETIM KOMITESI ETKINLIĞi VE iHTTYYATLILIK KAVRAMI}

\section{ÖZET}

Amaç- Bu çalışmanın temel amacı, denetim komitesi etkinliği ile finansal raporlama kalitesinin göstergesi olarak belirlenen şirketlerin ihtiyatlılık düzeyleri arasındaki ilişki incelemektir.

Yöntem- Bu amaca ulaşmak için, 2008-2017 yılları arasında BiST'te işlem gören 233 finansal olmayan şirketten elde edilmiş 1903 adet gözlem kullanılarak panel veri regresyon analizi yapılmıştır.

Bulgular- Araştırma bulgusu, denetim komitesi etkinliğinin ihtiyatılıı ile pozitif ilişkili olduğunu göstermektedir.

Sonuç- Yapılan analizler sonucunda, denetim komitesi etkinliği yüksek olan firmaların daha ihtiyatlı muhasebe politikaları izleyeceği ve buna bağı olarak finansal raporlama kalitesinin de artacağı söylenebilir.

Anahtar Kelimeler: Denetim komitesi etkinliği, ihtiyatlılık, kar/hisse senedi getirisi, panel veri analizi JEL Kodları: M40, M41, M42.

\section{GiRiş}

Denetim komitesi, özellikle denetimin kalitesi ve finansal raporlamanın gözetimi bakımından, bir firmanın genel kurumsal yönetim yapısının önemli bir bileşeni olarak görülmektedir (Fakhari ve Pitenoei, 2017: s.580). Denetim komiteleri, şirket ile iç denetim süreçlerini, muhasebe politikalarını ve ilkelerini, finansal raporlama kalitesini ve kamuoyunu bilgilendirme sürecini denetleyen bağımsız denetim arasındaki ilişkiyi düzenlemektedir. (Chen ve Li, 2013) Denetim komitesi işletmenin karşılaşabileceği riskleri azaltmak ve karşılaşılabilecek sorunların aşılması noktasında yönetime rehberlik etmek gibi bir rol üstlenmektedir (Dinç ve Abdioğlu, 2009:167). Denetim komitelerinin, denetim faaliyetleri ile ilgili doğrudan sorumlulukları bulunmamasına rağmen iç denetim ve bağımsız denetim süreçlerinin etkinliğini ve koordinasyonunu, 
muhasebe, finansal raporlama ve iç kontrol sistemlerin işleyişi ve yeterliliğini yönetim kurulu adına yürütmekle sorumludur (TÜSiAD, 2012:13).

Muhasebenin temel ilkelerinden biri olan ihtiyatlııı, yöneticilerin fırsatçı davranışlarını kısıtlayan ve muhasebe kayıtlarında yapılan ihlalleri hızla önleyerek finansal raporlama kalitesini arttıran önemli bir ilkedir (Zhong, 2016). 2010 yılında Uluslararası Muhasebe Standartları Kurulu (IASB) ve Finansal Muhasebe Standartları Kurulu (FASB) tarafından önerilen ortak kavramsal çerçeveden çıkarılmasına rağmen, günümüzde hala birçok şirketin benimsediği önemli bir ilkedir. Nitekim yapılan birçok ampirik çalışmalarda (Sultana, 2015; Kao ve Chu, 2016; Lim, 2011; LaFond ve Watts 2008) şirketlerin ihtiyatlı muhasebe politikaları izlediği görülmektedir.

Bu çalışmanın amacı, denetim komitesinin etkinliğinin şirketlerin ihtiyatlıık seviyelerine etkisini incelemektir. Denetim komitesi etkinliğinin ölçülmesi için denetim komitesi endeksi oluşturulmuştur. Bu endeks, literatür ve SPK'nın belirlediği denetim komitesi özellikleri dikkate alınarak tasarlanmıştır (Dezoort ve Salterio 2001); Ika ve Ghazali, 2012; SPK, 2011).

\section{LITERATÜR INCELEMESI}

\subsection{Denetim Komitesi Etkinliği}

Denetim komiteleri; denetim faaliyetleri ile ilgili doğrudan sorumlulukları bulunmamasına rağmen, iç denetim ve bağımsı denetim süreçlerinin etkinliğini ve koordinasyonunu, muhasebe, finansal raporlama ve iç kontrol sistemlerin işleyişi ve yeterliliğini yönetim kurulu adına yürütmekle sorumludur (TÜSIAD, 2012:13). Tüm bu görev ve sorumlulukları yerine getirebilmesi için denetim komitesinin etkin bir şekilde çalışması ve doğru dizayn edilmesi gerekmektedir. Denetim komitesinin etkinliğini belirleyen temel etkenlerin başında denetim komitesinin yapısı gelmektedir (Sultana, 2015). Nitekim öncelikle Amerika ve İngiltere gibi ülkelerde ve akabinde ülkemizde yapılan düzenlemeler ile; borsada işlem gören şirketlerin denetim komitesi kurması, komitelerde en az 2 üyenin bulunması, komite üyelerinin bağımsız olması, en az bir üyenin muhasebe veya finans konusunda uzman olması ve komitenin yılın belli aralıklarında toplanması zorunlu kılınmıştır (SPK, 2011).

Denetim komitesi etkinliğini ölçebilmek için yukarıdaki 4 temel özellik baz alınmıştır. Bu özelliklerinin eşit derecede önemli olduğu varsayımı altında, denetim komitesinin dört özelliğinin her biri için iki farklı bir puan atanarak ağıılıksız bir yaklaşım uygulanmaktadır:

$\checkmark$ DKBOYUT: Denetim komitesinde en az 2 üye varsa 1; aksi taktirde 0 puan

$\checkmark \quad$ DKBAĞ: Denetim komitesi üyelerinin çoğunluğu bağımsız üye ise 1 ; aksi taktirde 0 puan

$\checkmark$ DKTOPLANTI: Denetim komitesi bir dönemde 4'ten fazla toplantı gerçekleştirdiyse 1; aksi taktirde 0 puan

$\checkmark$ DKMFU: Denetim komitesinde en az 1 muhasebe veya finans alanında uzman üye varsa 1; aksi taktirde 0 puan

Belirli bir firmanın denetim komitesi etkinliği, dört özelliğin ortalama puanı hesaplanarak ölçülmüştür:

DKETKINLIK: (DKBOYUT + DKBAĞ + DKTOPLANTI + DKMFU) / 4

\subsection{Ihtiyatlılık}

Geleneksel olarak ihtiyatılık, "kârları dikkate alma fakat bütün zararları dikkate al" ifadesiyle açıklanabilir (Acar ve Aktürk, 2009). Daha genel bir ifade ile, ihtiyatılıık "şirketlerin finansal tablolardaki iyi haberleri kötü haberlere göre daha yüksek derecede doğrulama ihtiyacı içinde olma" olarak tanımlamaktadır (Basu, 1997). İhtiyatılık ilkesine göre karlar, kötü haberleri iyi haberlere göre daha hızlı yansıtmaktadır. İyi haberler, zaman içinde kademeli olarak kabul edilirken, kötü haberler fazla doğrulama yapılmadan kabul edilmektedir. Yani iyi haberler ile kötü haberler arasında zamanlıık asimetrisi söz konusu olmaktadır.

Yapılan birçok ampirik çalışmada, ihtiyatılıı̆ın, kar yönetimi, bilgi asimetrisi, vekalet maliyeti gibi sorunları azalttığını ve şirketlerde kurumsal yönetim anlayışını geliştirdiği ortaya konmuştur. LaFond ve Watts (2008), ihtiyatılıı̆a, özellikle finansal raporlama aşamasında ihtiyaç duyulduğunu ve yöneticilerin fırsatçı davranışlarını engellediği için finansal raporlardaki bilgilerin güvenilirliğini ve doğruluğunu arttırdığı savunmaktadır. Ancak, García vd., (2012); Fengyi vd., (2014) gibi yazarlar, ihtiyatılılı ile kar yönetimi arasında pozitif bir ilişki olduğunu ve intiyatlılığın kar manipülasyonuna neden olduğunu savunmaktadır. FASB (2010) ihtiyatııı̆ı̆n, önyargılı bilgilerin muhasebeleştirilmesine neden olduğunu ve muhasebenin temel ilkelerinden olan tarafsızlık ilkesini zedeleyen sonuçlar doğurduğunu ileri sürmektedir. Ayrıca, Pae (2007) ihtiyatlıık uygulamaları yüzünden varlıklar olduğundan daha düşük gösterildiğini ve bunun sonucunda finansal tablolarda yanlış bilgiler sunulduğunu savunmaktadır. Son olarak, günümüzde gerçeğe uygun değer yönteminin piyasaya, yatıımcılara ve diğer paydaşlara şirket hakkında daha gerçekçi bilgiler sunması ve ihtiyatlılığın bu bilgilere ulaşımı sınırlandırdığı ve hatta engellediği düşüncesi ihtiyatlılğa olan bakış açııını değiştirmiştir. Tüm bunların sonucunda, 2010 yılında Uluslararası Muhasebe Standartları Kurulu tarafından kavramsal çerçeveden çıkartılmıştır.

\subsection{Denetim Komitesi ve ihtiyatılıık Üzerine Yapılan Çalışmalar}

Şrketlerin muhasebe ve raporlama sürecinin gözetiminde önemli bir rol üstlenen denetim komiteleri, finansal tabloların oluşturulmasında ve kamuoyuna finansal bilgilerin sunulmasında ihtiyatlı muhasebe politikaları izlemesi gerekmektedir. Muhasebenin temel ilkelerinden birisi olan ihtiyatılıık kavramı gereği, şirketler gerçekleşmesi olası olan kötü durumları finansal tablolara daha hızı aktarırken, gerçekleşmesi olası iyi durumları birçok doğrulama kademesinden geçirdikten sonra finansal tablolara aktarmaktadır (Watts, 2003). Bunun sonucunda daha şeffaf, daha güvenilir ve daha kaliteli finansal raporlar ortaya çıkmaktadır. Denetim komitesi ve ihtiyatık arasındaki ilişkiye yönelik yapılan çalışmalar incelendiğinde (Sultana, 2015; LaFond ve Watts 2008; Kao ve Chu, 2016) denetim komitesi özellikleri ile ihtiyatlılık arasında güçlü bir ilişkinin olması beklenmektedir. 
Denetim komitesi ve ihtiyatılık arasındaki ilişkiye yönelik yapılan çalışmalara bakıldığında (Sultana, 2015; LaFond ve Watts 2008; Kao ve Chu, 2016) denetim komitesinin 4 temel özelliğine (Bağımsızığı, finansal uzmanlı̆̆ı, boyut, toplantı sıklğı) odaklanıldığı görülmektedir. Bu nedenle çalışmada denetim komitesi etkinliğinin ihtiyatılık üzerine etkisini ölçmek için bu 4 temel denetim komitesi özelliklerine odaklanılmışır. Ayrıca çalışmamızda, denetim komitesi özellikleri ile arasında tamamlayıcılık ilişkisi bulunan yönetim kurulu özellikleri (Yönetim kurulu boyutu, bağımsızlğı, CEO-Yönetim kurulu başkanı ayrımı ve denetim kalitesi) ve firmaya özgü özellikler (firma büyüklüğü, piyasa değeri / defter değeri ve kaldıraç oranı) kontrol değişkeni olarak kullanılmıştır. Araştırma hipotezimiz şu şekilde oluşturulmuştur:

H1: Denetim komitesi etkinliği firma ihtiyatlılık düzeyini pozitif etkiler.

\section{YÖNTEM}

Bu çalışmanın amacı, denetim komitesinin etkinliğinin şirketlerin ihtiyatılık seviyelerine etkisini incelemektir. Literatürde ihtiyatlıık seviyesinin belirlenmesi ile ilgili birçok model geliştirilmiştir. Bu modeller arasında Kar / Hisse Senedi Getirisi modeli (Basu Modeli), literatürdeki çalışmalarda en çok tercih edilen yöntem olmuştur. Firma hakkında her türlü haberi hızlı bir şekilde yansıtabilen bir araç olan hisse senetlerinin üzerinden ihtiyatııı̆ı̆ın ölçülmesini sağlayan bu model, çalışmamızın araştırma yöntemi olarak tercih edilmiştir. Basu modeli olarak da anılan bu modelle, hisse başına kar ile hisse senedi getirisi arasındaki ilişkiden yola çıkarak şirketlerin ihtiyatılıı seviyesi belirlenebilmektedir (Zhong, 2016).

Basu modeli olarak da bilinen aşağıdaki regresyon formülü, ihtiyatılık düzeyini ölçmek için kullanılır:

$X_{i t} / P_{i t}=\beta_{0}+\beta_{1} D R_{i t}+\beta_{2} R_{i t}+\beta_{3} R_{i t} D R_{i t}+\varepsilon_{i t}$

$\mathrm{X}_{\mathrm{it}}=\mathrm{t}$ yılı i firması için hisse başına kar

$P_{i t}=t$ yılı i firması için hisse senedi açılış fiyatı

$\mathrm{R}_{\mathrm{it}}=\mathrm{t}$ ylı $\mathrm{i}$ firması için hisse senedi getirisi

$D R_{i t}=R$ negatifse $D R=1, R$ pozitifse $D R=0$

\section{BULGULAR}

\subsection{Tanımlayıcı İstatistikler}

Aşağıda gösterilen Tablo 1'de regresyon modelinde yer alan değişkenlere ait ortalama, standart sapma, maksimum ve minimum değerlerine yer verilmiştir. Tablo 1'ye göre, şirketlerin denetim komitelerinin etkinlik endeksinin ortalama 0.709 'luk bir değer almıştır. Bu durum, denetim komitelerinin etkili olabilecek şekilde dizayn edildiğini ortaya koymaktadır.

Tablo 1: Tanımlayıcı İstatistikler

\begin{tabular}{|c|c|c|c|c|}
\hline Değişken adı & Ortalama & Standart sapma & Minimum değer & Maksimum değer \\
\hline$X / P$ & 0.117 & 1.042 & -14.428 & 23.488 \\
\hline $\mathbf{R}$ & -5.211 & 105.449 & -3722.63 & 96.595 \\
\hline DKETKINLIK & 0.709 & 0.235 & 0 & 1 \\
\hline YKBÜYÜK & 6.962 & 2.062 & 3 & 15 \\
\hline YKBAĞ & 0.236 & 0.150 & 0 & 0.60 \\
\hline YKB-CEO & 0.768 & 0.422 & 0 & 1 \\
\hline DENKAL & 0.541 & 0.498 & 0 & 1 \\
\hline PD/DD & 1.772 & 0.404 & 1 & 29.257 \\
\hline KAL & 0.513 & 0.404 & 0.006 & 8.674 \\
\hline ŞiRKETBÜY & 19.555 & 1.694 & 14.331 & 24.952 \\
\hline
\end{tabular}

\subsection{Korelasyon Analizi}

Aşağıda gösterilen Tablo 2, tüm örneklem için pearson korelasyon matrisi sonuçlarını göstermektedir. Sonuçlar, denetim komitesi etkinliğinin (bağımsız değişken) hisse başına kar / hisse fiyatı (bağımlı değişken) ile istatiksel olarak anlamlı ve pozitif ilişkili olduğu göstermektedir. 
Tablo 2: Korelasyon Tablosu

\begin{tabular}{|c|c|c|c|c|c|c|c|c|c|c|}
\hline & $X / P$ & $\mathbf{R}$ & $\begin{array}{c}\text { DK } \\
\text { ETKiNLiK }\end{array}$ & $\begin{array}{c}\text { YK } \\
\text { BÜYÜK }\end{array}$ & YKBAĞ & YKB-CEO & DENKAL & PD/DD & KAL & $\begin{array}{l}\text { ŞiRKET } \\
\text { BÜY }\end{array}$ \\
\hline $\mathrm{X} / \mathrm{P}$ & 1 & & & & & & & & & \\
\hline HSGETIRi & $0.209 *$ & 1 & & & & & & & & \\
\hline DKETKINLI & $0.052 * *$ & $0.050 * *$ & 1 & & & & & & & \\
\hline YKBÜYÜK & $0.125^{*}$ & $0.082^{*}$ & $0.113^{*}$ & 1 & & & & & & \\
\hline YKBAĞ & $-0.092 *$ & 0.018 & $0.590 *$ & $-0.101^{*}$ & 1 & & & & & \\
\hline YKB-CEO & $0.055^{* *}$ & $0.051^{* *}$ & 0.024 & $-0.235 *$ & $-0.069 *$ & 1 & & & & \\
\hline DENKAL & $0.096^{*}$ & $0.075^{*}$ & 0.003 & $0.311^{*}$ & $-0.105 *$ & 0.289 & 1 & & & \\
\hline PD/DD & $-0.040 * * *$ & $0.140 *$ & $0.052^{* *}$ & -0.033 & 0.008 & $-0.065 *$ & $0.041^{* * *}$ & 1 & & \\
\hline KAL & $-0.217^{*}$ & -0.036 & $0.053^{* *}$ & $-0.072 *$ & $0.075^{*}$ & -0.035 & -0.016 & $-0.133^{*}$ & 1 & \\
\hline ŞİRKETBÜY & $0.205^{*}$ & $0.120 *$ & 0.026 & $0.523^{*}$ & 0.000 & 0.241 & $0.446 *$ & $0.161 *$ & $0.085^{*}$ & 1 \\
\hline
\end{tabular}

\subsection{Regresyon Analizi}

Tablo 3, firmaların ihtiyatlılık düzeylerine etki etmesi beklenen bağımsız değişken ve kontrol değişkenlerinin kullanıldığı regresyon analiz sonuçlarını göstermektedir. Tablo 3'te gösterilen analiz sonuçları, denetim komitesi etkinliğinin firma ihtiyatlılık düzeyi ile istatiksel olarak anlamlı ve beklendiği gibi pozitif ilişkili olduğu göstermektedir. Başka bir ifade ile, denetim komitesi etkinliği arttıkça firmalar daha ihtiyatlı muhasebe politikaları izlemekte ve bu durum finansal raporlama kalitesini arttırmatadır

Tablo 3: Regresyon Sonuçları

\begin{tabular}{|c|c|c|c|c|c|}
\hline Değişkenler & Beklenen İşaret & Katsayı & t değeri & p değeri & VIF \\
\hline Sabit Sayı & & -0.142 & -0.63 & 0.528 & \\
\hline HSGETIRi** & + & 0.004 & 2.07 & 0.040 & 1.54 \\
\hline DKETKINLIK** & + & 0.001 & 1.97 & 0.050 & 1.64 \\
\hline YKBÜYÜK & + & -0.000 & -1.20 & 0.233 & 1.52 \\
\hline YKBAĞ & + & -0.002 & -1.58 & 0.117 & 1.65 \\
\hline YKB-CEO & + & -0.000 & -0.71 & 0.477 & 1.13 \\
\hline DENKAL & + & -0.000 & -1.07 & 0.286 & 1.34 \\
\hline PD/DD & + & 0.000 & 0.43 & 0.667 & 1.66 \\
\hline $\mathrm{KAL}^{* *}$ & - & -0.002 & -2.08 & 0.039 & 1.04 \\
\hline ŞíRBÜYÜK & + & -0.000 & -0.86 & 0.392 & 1.02 \\
\hline Gözlem Sayısı & 1903 & & & & \\
\hline F Değeri & 6.22 & & & & \\
\hline Düzeltilmiş $\mathbf{R}^{2}$ & 0.444 & & & & \\
\hline
\end{tabular}

\section{SONUÇ VE ÖNERILER}

Yazın taraması incelendiğinde, denetim komitesi etkinliğinin ihtiyatlılığı pozitif bir şekilde etkileyeceğine dair araştırmalar yer almaktadır (Sultana, 2015; Krishnan ve Visvanathan, 2008; Kao ve Chu, 2016). Literatür incelemesi ile bu araştırmanın sonuçları arasında paralelik olduğu görülmektedir. Yapılan analizler neticesinde elde edilen sonuç, firmaların denetim komitesi etkinliği arttıkça, daha ihtiyatlı muhasebe politikaları izlediklerini ortaya koymaktadır. Bu sonuçlara göre, denetim komitesi üye sayısı, bağımsızlığı, muhasebe veya finans konusunda uzmanlığı ve toplantı sayısı gibi denetim komitesi özelliklerinin ve bu özelliklerin doğru bir kombinasyonu, komitelerin görev ve sorumluluklarını daha iyi bir şekilde yerine getirmesini sağlar ve komitelerin etkinliği arttırır. Etkin bir denetim komitesi ise finansal raporlama kalitesinin en önemli özelliklerinden birisi olan ihtiyatlılık seviyesinin artmasına neden olur. 
Bu araştırma ile birlikte, araştırmacılara ve uygulayıcılara çeşitli öneriler sunulmuştur. İhtiyatılık, her ne kadar 2010 yılında ortak kavramsal çerçeveden çıkarılmış olsa da günümüzde hala birçok şirketin benimsediği önemli bir ilkedir. Gelecek çalışmalarda bu durum analiz edilerek şirketlerin ihtiyatı muhasebe politikalaırını ortak kavramsal çerçeveden çıkarılmasına rağmen neden takip ettikleri incelenmelidir. Ayrıca önemli bir ihtiyatlılık ölçütü olan Basu modeli dışında kullanılabilecek diğer yöntemler ile borsada işlem görmeyen firmalar bazında ihtiyatlılık düzeyi araştırılabilir.

\section{KAYNAKÇA}

Acar, D. ve Aktürk, A. (2009). Muhasebede İhtiyatlılık Kavramı ve IMKB Sınai Endeksinde İşlem Gören İşletmelerde İhtiyatlılık Üzerine Bir Araştırma. Afyon Kocatepe Üniversitesi İktisadi ve İdari Bilimler Fakültesi Dergisi, 11 (1), p.77-90.

Basu, S. (1997). The Conservatism Principle and the Asymmetric Timeliness of Earnings. Journal of Accounting and Economics, 24 (1), p. 337.

Chen, F. ve Li, Y. (2013). Voluntary Adoption of More Stringent Governance Policy on Audit Committees: Theory and Empirical Evidence. The Accounting Review, 88(6), p. 1939-1969.

DeZoort, F.T., Salterio, S.E. (2001), The effects of corporate governance experience and financial reporting and audit knowledge on audit committee members' judgments. Auditing: A Journal of Practice\& Theory, 20(2), p. 31-47.

Dinç, E. ve Abdioğlu, H. (2009), İşletmelerde Kurumsal Yönetim Anlayışı ve Muhasebe Bilgi Sistemi iliş̧isi: IMKB-100 Şirketleri Üzerine Ampirik Bir Araştırma, Balıkesir Üniversitesi Sosyal Bilimler Enstitüsü Dergisi, Cilt: 12, Sayı:21, s.158.

Fakhari H., Pitenoei Y. R. (2017). The Impact of Audit Committee and Its Characteristics on the Firms Information Environment, Iranian Journal of Management Studies (IJMS). 10(3), p. 577-608.

Fengyi L., Chung-Min W., Tzu-Yi F. ve Jheng-Ci W. (2014). The Relations Among Accounting Conservatism, Institutional Investors and Earnings Manipulation, Economic Modelling, 37: 164-174.

Financial Accounting Standards Board (FASB) (2010). Statement of Financial Accounting Concepts No. 8, Conceptual framework for financial reporting. Norwalk, CT: FASB.

García L., J., M., García O., B. ve Penalva, F. (2012). Conditional Conservatism and the Limits to Earnings Management. SSRN Electronic Journal Ika, S. ve Ghazali, N. (2012). Audit Committee Effectiveness and Timeliness of Reporting: Indonesian Evidence. Managerial Auditing Journal, Vol. 27 (4), p. 403-424

Kao, H. ve Chu, T. (2016). Audit committee, supervisor system and accounting conservatism. International Research Journal of Applied Finance, 7(9), p. 202-219.

Krishnan, G. and Visvanathan, G. (2008). Does the SOX Definition of an Accounting Expert Matter? the Association between Audit Committee Directors' Accounting Expertise and Accounting Conservatism, Contemporary Accounting Research Vol. 25(3), p. 827-857.

Lafond, R., \& Watts, R. (2008). The Information Role of Conservatism, The Accounting Review, 83(2), p. 447-478.

Lim R. (2011). Are corporate governance attributes associated with accounting conservatism?, Accounting and Finance, 51(4), p. 1007-1030.

Pae, J., Thornton, D. ve Welker, M. (2004). The Link Between Earnings Conservatism and Balance Sheet Conservatism. Queen's University Working Paper.

SPK, (2011). Kurumsal Yönetim İlkelerinin Belirlenmesine ve Uygulanmasına İlişkin Tebliğ, http://www.spk.gov.tr/duyurugoster.aspx?aid=20111011\&subid=0\&ct=c (Erişim Tarihi: 30.03.2019)

Sultana, N. (2015). Audit Committee Characteristics and Accounting Conservatism, International Journal of Auditing, 19, p. 88-102.

TÜSIAD. (2012). Uygulama Örnekleri ile Birlikte A'dan Z’ye Denetim Komiteleri, Türk Sanayicileri ve İş adamları Derneği, Haziran, Yayın No:527.

Watts, R.L. (2003). Conservatism in Accounting Part I: Explanations and Implications. Accounting Horizons, 17 (3), p. $207-221$.

Zhong, Y. ve Li, W. (2016). Accounting Conservatism: A Literature Review. Australian Accounting Review, 27, p. 195-213. 